\title{
Application of anaerobic baffled reactor for agro- industrial wastewater treatment
}

\section{Opinion}

Agro-industry is one of the major kinds of industries that are very important for developing countries such as the Southeast Asian nations. The manufacturing processes used in these industries typically generate large amounts of wastewater. The main pollutants present in this wastewater are organic matter and nitrogen. Further, some agro-industrial wastewater also contains persistent substances such as suspended solids, lipids, microbial inhibitors such as ammonia, longchain fatty acids, and sulfate. Currently, nearly all agro-industries in developing countries use the conventional lagoon system for wastewater treatment because of its low operational cost and ease of maintenance. However, this system has some disadvantages such as long hydraulic retention time (HRT), low effluent quality, malodor, groundwater pollution, and greenhouse gas (GHG) emission. On the other hand, closed anaerobic systems can achieve both reduction of GHG emission and recovery of methane, which is a major GHG, as energy during wastewater treatment. Nowadays, the up-flow anaerobic sludge blanket (UASB) reactor is applied to many kinds of industrial wastewater treatment as a high-rate system. However, application of the UASB reactor to agro-industrial wastewater treatment causes several problems such as sludge wash-out, clogging, and sulfide inhibition because of wastewater characteristics like high lipid content (for example, palm oil mill effluent), high solid content (for example, wastewater from natural rubber processing), and high sulfate content (for example, molasses wastewater). ${ }^{1-3}$ Therefore, appropriate pretreatment systems are required when UASB reactors are used for agro-industrial wastewater treatment. In contrast, the anaerobic baffled reactor (ABR), which is a high-rate closed anaerobic wastewater treatment system, has more applicability for agro-industrial wastewater than the UASB reactor. The ABR can separate the anaerobic digestion phases of organic matter, such as hydrolysis, acidification, sulfate reduction, and methane production, by compartmentalization. Furthermore, the ABR exhibits high performance for solid-liquid separation by alternative arrangement of up-flow and down-flow compartments. Consequently, the ABR can separate HRT and solid/sludge retention time (SRT) without holdback carrier for the retained sludge, and prevent the sludge wash-out. In addition, the $\mathrm{ABR}$ does not require any moving parts and mechanical mixing. Therefore, the ABR has some advantages for agro-industrial wastewater treatment including low operating and capital costs, low excess sludge generation, prevention of sludge wash-out, ease of maintenance, and high stability under organic shock loading when compared with other high-rate anaerobic systems such as UASB, expanded granular sludge bed (EGSB) and membrane bioreactor (MBR). ${ }^{4}$ Figure 1 shows the concept of an ABR for agro-industrial wastewater treatment. The key operational principle behind the ABR is the separation of agro-industrial wastewater into persistent (such as solid and lipid) and degradable substances (such as carbohydrate and soluble organic matter). Persistent substances in the wastewater can be recovered from the top of each ABR compartment as energy and material resources. In addition, residual persistent substances are accumulated and degraded biologically in the ABR with long SRT. On the other hand, biodegradable substances are promptly

\author{
Volume I Issue I - 2017
}

\author{
Daisuke Tonkawa \\ Department of Civil and Environmental Engineering, National \\ Institute of Technology, Kure College, Japan
}

\begin{abstract}
Correspondence: Daisuke Tonkawa, Department of Civil and Environmental Engineering, National Institute of Technology, Kure College, Aga-minami, Kure, Japan, Tel +8I-823-73-8955,
\end{abstract} Email tanikawa@kure-nct.ac.jp

Received: July 29, 2017 | Published: August 18, 2017

degraded anaerobically and converted to methane in the ABR itself. Consequently, high-rate treatment of agro-industrial wastewater can be achieved. In the case of lipid-rich wastewater such as palm oil mill effluent, the lipid, which acts as persistent and inhibitive organic matter in the wastewater, can be separated and recovered as combustible scum at the inlet compartment of the ABR. ${ }^{5}$ In the treatment of wastewater from natural rubber processing, the compartments of the ABR near the inlet serve as rubber traps from which rubber material can be recovered and reactor clogging can be prevented. ${ }^{6,7}$ Previous studies describe the treatment of sulfate-rich wastewater including molasses and concentrated latex wastewater using a two-stage system that separates the biodegradation process into a sulfate reduction phase and a methane production phase to prevent hydrogen sulfide inhibition of methane-producing archaea. ${ }^{3-8}$ The ABR, on the other hand, can separate the sulfate-reduction and methane-production phases using different compartments within a single-stage reactor. Furthermore, the wastewater capacity of an ABR can be increased by the addition of up-flow and/or down-flow tanks as compartments. Therefore, the ABR can be applied as an appropriate treatment system for agro-industrial wastewater.

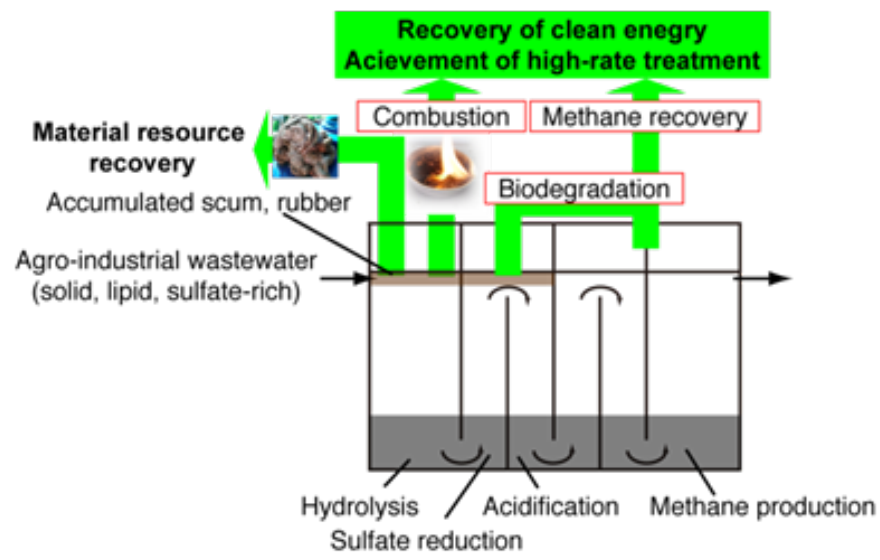

Figure I Concept of an ABR for agro-industrial wastewater treatment.

\section{Acknowledgment}

This research was supported by the JSPS KAKENHI (Grant No.: 16K18176), and Iwatani Foundation's Research Grant, Japan. 


\section{Conflict of interest}

None.

\section{References}

1. Gomes DRS, Papa LG, Cichello GCV, et al. Effect of enzymatic pretreatment and increasing the organic loading rate of lipidrich wastewater treated in a hybrid UASB reactor. Desalination. 2011;279:96-103.

2. Nguyen NH, Luong TT. Situation of wastewater treatment of natural rubber latex processing in the Southeastern region, Vietnam. $J$ Viet Env. 2012;2(2):58-64.

3. Yobolsai C, Choeisai P, Visedkaew P, et al. Anaerobic treatability of cane molasses based bio-ethanol distillery wastewater mixed with cane sugar mill wastewater by two phase multi-stage upflow anaerobic sludge blanket reactor. Journal of Sustainable Energy \& Environment. $2015 ; 6: 75-79$
4. Barber WP, Stuckey DC. The use of the anaerobic baffled reactor (ABR) for wastewater treatment: A review. Water Research. 1999;33(7):1559-1578.

5. Tanikawa D, Yokote N, Nakahara K, et al. Evaluation of process performance for lipid-rich wastewater treatment using a combination system of an anaerobic baffled reactor and aerobic trickling filter. Journal of Water \& Environment Technology. 2016;14(2):90-95.

6. Watari T, Nguyen TT, Tsuruoka N, et al. Development of BR-UASBDHS system for natural rubber processing wastewater treatment. Evironmental technology. 2016;37(4):459-465.

7. Tanikawa D, Syutsubo K, Watari T, et al. Greenhouse gas emissions from open-type anaerobic wastewater treatment system in natural rubber processing factory. Journal of Cleaner Production. 2016;119:32-37.

8. Tanikawa D, Syutsubo K, Hatamoto M, et al. Treatment of natural rubber processing wastewater using a two-staged up-flow anaerobic sludge blanket and down-flow hanging sponge system. Water Sci Technol. 2016;73(8):1777-1784 